Dhaka Univ. J. Sci. 60(2): 253-257, 2012 (July)

\title{
Rural to Urban Migration and Household Living Conditions in Bangladesh
}

\author{
M. Ershadul Haque and M. Mazharul Islam
}

Department of Statistics, Biostatistics \& Informatics, Dhaka University, Dhaka-1000, Bangladesh

Received on 12. 10. 2011. Accepted for Publication on 22. 02. 2012.

\begin{abstract}
This study examines the relationships between rural to urban migration status and household living conditions, using the 2007 Bangladesh Demographic and Health Survey (BDHS) data.

The analysis finds significant living condition advantage of rural-urban migrants and urban natives over rural-natives, primarily linked to migration selectivity by education and occupation. Once the independent effects of education and occupation are controlled, association between migration status and living conditions remain significant but living condition advantage of rural-urban migrants and urban natives over rural natives fall down. The results imply that promoting higher education and opportunities for employment outside the agricultural or labour sectors (pull factor) are more likely to yield improved living conditions in Bangladesh.
\end{abstract}

Keywords: Rural-Urban migrants, Rural natives, Urban natives, Wealth index, Factor score, Bi-serial correlation, OLS regression analysis.

\section{Introduction}

Increases in internal migration associated with economic and political transitions in countries of Asia, Africa, Latin America and the Pacific ${ }^{1}$ have made migration a salient feature of life in developing countries.

The study focuses on household living conditions on the premise that poverty is about people and its detrimental outcomes play out in the living conditions of people in the household ${ }^{2}$. The central hypothesis of the study is that if the "benefits-of-migration" model is true, then the migration status of the women of a household will affect the living conditions of the household. Population redistribution add the growth of cities and towns are expected to serve as important catalysts for national development and raise the living standards of migrants and their households ${ }^{1}$. This study employs multiple regression models to examine the association between migration and household living conditions, controlling for individual and socioeconomic characteristics.

The goals of the current study are: to examine the impact of internal migration on socioeconomic characteristics of the migrants in Bangladesh and to examine the relationship between household living conditions and internal migration to the extent to which internal migration contributes to a reduction in poverty of our country.

The analysis of this study utilizes data of the 2007 Bangladesh Demographic and Health Survey (BDHS). The women were classified into three categories according to their migration status: Urban native: Women born and currently living in an urban area. Rural native: Women born and currently living in a rural area. RuralUrban migrant: Women born in a rural area but currently living in an urban area. The outcome variable in this analysis is household living conditions. The survey data set did not have income measures or consumption expenditures, which are conventionally used as indicators of household economic status. Also, the traditional concept of poverty, which places emphasis on income, has been identified in developing countries as too narrow ${ }^{3}$, and often there are issues with the validity of income data due to reporting errors. Montgomery ${ }^{4}$ have noted that in developing countries, households often draw their incomes from multiple sources that can change from year to year and even from season to season. The transitory nature of some employment, coupled with the uncertainty of net economic return, makes it implausible to regard any one year's income as representative of the incomes earned over the longer time span in which demographic decisions are made. In BDHS report an index of household economic status was created and used as background characteristics with information on household ownership of assets and use of selected services.

The economic status index used here was developed and tested in a large number of countries in relation to iniquities in household income, use of health services, and health outcomes $^{5}$. It is an indicator of the level of wealth that is consistent with expenditure and income measures ${ }^{6}$. The wealth index was constructed using principal components analysis ${ }^{7}$. Asset information was collected with the 2007 BDHS Household Questionnaire and covered information on household ownership of a numbers of consumer items, ranging from a television to a bicycle, as well as dwelling characteristics, such as sources of drinking water, sanitation facilities, and type of material used for flooring. Each asset was assigned a weight (factor score) generated through principal components analysis, and the resulting asset scores were standardized in relation to a normal distribution with a mean of zero and standard deviation of one $\mathrm{e}^{5}$.

\section{Data, Measures and Methods}

The study is conducted using Bangladesh Demographic and Health Survey (BDHS) 2007 data. The dependent variable of this study is the standardized weight (ranging from -1.14 to 3.72) of wealth index factor score. The higher negative scores indicate "poorest" economic status and higher positive score indicates better and "richest" economic status. Migration 
status with three categories: rural natives, rural-urban migrants and urban natives plays role as an explanatory variable. The study controls for socioeconomic and demographic factors, which includes education, age, occupation, number of living children (a close proxy for household size), religion and region.

Education is the main source of human capital formation and ultimately a crucial tool for poverty avoidance. It is expected that mobility, economic status and development of households will vary across different levels of educational attainment. Education is coded into four categories: no education, primary, secondary and higher education. The role of age is also important. The age variable is in three cohorts: 15-19 (reference category), $20-29,30-39$ and 40-49. The religion of respondent is presented in two categories: Muslim, Others. Number of living children is in three categories: less or equal 2 children, 3-4 children and 5 children or above. As children ever born (CEB) and number of living children are highly correlated, the CEB is not considered in the regression model. In terms of occupation, the distinction is made among unemployed/housewife, agricultural/factory workers, professional and others. Considerable differences exist among regions with respect to economic potentials, population densities, socioeconomic development and urbanization.

\section{Analytical Methods}

The analysis of data includes a description of the study population followed by a bivariate analysis of the correlations between all categories of independent variables and living condition index. Finally a multivariate analysis using Ordinary Least Squares (OLS) is conducted to determine the potential factors for living conditions. The multiple linear regression model used for this purpose is:

$\mathrm{Y}=\beta_{0}+\Sigma \beta_{1 \mathrm{k}}$ (Migration status $)_{\mathrm{k}}+\Sigma \beta_{2 \mathrm{k}}(\text { Education })_{\mathrm{k}}+$ $\Sigma \beta_{3 \mathrm{k}}(\text { Age })_{\mathrm{k}}+\Sigma \beta_{4 \mathrm{k}}$ (Occupation) $)_{\mathrm{k}}+\Sigma \beta_{5 \mathrm{k}}$ (Living children $)_{\mathrm{k}}+\Sigma \beta_{6 \mathrm{k}}(\text { Religion })_{\mathrm{k}}+\Sigma \beta_{7 \mathrm{k}}(\text { Region })_{\mathrm{k}}+\varepsilon$.

where, k represents categories of the predictors.

In consideration of multicollinearity concerns, a multicollinearity test was conducted for all variables in the regression. The collinearity does not indicate a redundant predictor among all categories of independent and control variables (Table not shown).

\section{Results}

The table for descriptive statistics was not shown for space limitation. It was found that the distribution of migration status: 25.3 percent of the study population are rural-urban migrants, 58.9 percent are rural natives and 15.8 percent are urban natives. Among the respondent 70.9 percent are unemployed/housewife, 3.9 percent are agricultural/factory workers, 1.8 percent are professional and 23.1 percent are working in other sectors. The study population is with very low levels of education. Among rural natives, 37.7 percent have no education and 32.0 percent attained primary education, 27.6 percent have secondary education and 2.6 percent attained higher or more education. For rural-urban migrants these are 31.1 percent, 29.3 percent, 31.9 percent and 7.6 percent respectively and for urban natives these are 17.3 percent, 22.3 percent, 33.4 percent and 22.0 percent respectively. It reiterates the low levels of literacy in the country. Among rural natives 72.8 percent respondents have the number of children less than $3,18.9$ percent have 3 or 4 , and 8.2 percent have 5 or more children. The results for migrants are 76.1 percent, 18.5 percent and 5.5 percents respectively, while for urban native these are 83.3 percent, 14.4 percent and 2.3 percent respectively. Among the working respondents 27.9 percent of the respondents work at the agricultural sector, 40.7 percent are labourer and 31.4 percent are doing jobs other (business, professional etc.). The outcome of working status is also driven for rural natives, rural-urban migrants and urban natives among whom only 67.9, 71.4 and 74.9 percent are unemployed/housewife respectively; 3.9, 4.0 and 4.8 percent are agricultural/factory workers respectively. Table 1 shows the bi-serial correlations between each category of independent variables and wealth index factor scores (households living conditions). This reveals that being a ruralurban migrant or urban native, professional/housewife, living in Dhaka or Chittagong division, having children less than 3, aged 30 years or over and having secondary or higher education are all positively correlated with living conditions. In order to determine the net effects of the independent and control variables, three multivariate regression models are considered and the results are given in Table 2. In Model 1, with rural-native as the reference category, the outcome replicates the result of the bivariate analysis above, rural-urban migrants and urban natives show significantly better living conditions than rural natives. The mean wealth index factor scores for rural urban migrants and urban natives are 0.775 and 1.753 units higher compared to reference category respectively. These are found statistically significant. The control variables education level, age group, and occupation are included in Model 1, which we refer to Models 2. Model 3 added number of living children, religion and region as the control variables with other independent variables considered in Model 2. From model 2 and 3 the association between living conditions and selected variables show that those who have no education possess the worst living conditions and the living condition improves significantly as the education level increases; those who are of 20 years or less old have the worst living conditions and the living condition improves significantly as they grow older; looking at the association between household structure and living conditions, the outcome indicates a marginal advantage for small sized households (<3 living children) compared to medium-sized (34 living children) and large-sized households (5 or more living children). 


\section{Discussion and Conclusions}

It was found from bivariate analysis that wealth index factor scores is negatively correlated with rural natives but positively correlated with both urban natives and rural urban migrants. But urban natives have higher degree correlation than rural urban migrants. All these correlations are statistically significant. The multivariate results show that the significant living conditions advantage of migrants over rural natives primarily due to selectivity into migration status by education and occupation. A step by step introduction of each variable into the regression pinpoints education and access occupation as the individual variables mostly responsible for varying effects of migration status across models. When education was introduced into the analysis, the significant advantage observed for rural-urban migrants and urban natives over rural natives but the values of regression coefficients decrease. Further, when occupation was introduced into the model along with education,

Table 1. Bi-serial correlations of categories of independent variables and wealth index factor scores.

\begin{tabular}{|l|l|}
\hline Independent variables & Correlation coefficient $(\mathbf{r})$ \\
\hline Migration status & \\
Rural native & $-0.716^{* *}$ \\
Urban native & $0.839^{* *}$ \\
Rural-Urban migrant & $0.238^{* *}$ \\
Education level & \\
No education & $-0.374^{* *}$ \\
Primary & $-0.195^{* *}$ \\
Secondary & $0.257^{* *}$ \\
Higher & $0.764^{* *}$ \\
Age group & \\
\hline$<20$ & $-0.110^{* *}$ \\
20-29 & -0.011 \\
$30-39$ & $0.054^{* *}$ \\
$40+$ & $0.048^{* *}$ \\
Occupation & \\
Unemployed/housewife & $0.220^{* *}$ \\
Agricultural/Factory workers & $-0.097 * *$ \\
Professional & $0.532^{* *}$ \\
Others & $-0.295^{* *}$ \\
No. of living children & \\
\hline$<3$ & $0.154^{* *}$ \\
3-4 & $-0.104^{* *}$ \\
5+ & $-0.170^{* *}$ \\
Religion & \\
Muslim & 0.026 \\
Others & -0.026 \\
Region & \\
Dhaka & $0.184^{* *}$ \\
Chittagong & $0.034^{* *}$ \\
Khulna & -0.024 \\
Sylhet & 0.014 \\
Barisal & $-0.178^{* *}$ \\
Rajshahi & $-0.085^{* *}$ \\
\hline
\end{tabular}

Levels of Statistical Significance: $* * \mathrm{P}<0.01$ 
Table. 2. Beta coefficients of OLS regression analysis assessing associations between selected characteristics and wealth index factor scores.

\begin{tabular}{|c|c|c|c|}
\hline & Model (1) & Model (2) & Model (3) \\
\hline \multicolumn{4}{|l|}{$\underline{\text { Migration status }}$} \\
\hline \multicolumn{4}{|l|}{ Ref cat: Rural native } \\
\hline Rural-Urban migrant & $0.775^{* *}$ & $0.661 * *$ & $0.645^{* *}$ \\
\hline Urban native & $1.753 * *$ & $1.314 * *$ & $1.280 * *$ \\
\hline \multicolumn{4}{|l|}{ Education level } \\
\hline \multicolumn{4}{|l|}{ Ref cat: No education } \\
\hline primary education & & $0.184 * *$ & $0.224 * *$ \\
\hline Secondary education & & $0.678 * *$ & $0.705 * *$ \\
\hline Higher education & & $1.410 * *$ & $1.449 * *$ \\
\hline \multicolumn{4}{|l|}{ Age group } \\
\hline \multicolumn{4}{|l|}{ Ref cat: $<20$ yrs } \\
\hline $20-29$ yrs & & $0.079 * *$ & $0.099 * *$ \\
\hline $30-39$ yrs & & $0.298 * *$ & $0.373 * *$ \\
\hline $39+\mathrm{yrs}$ & & $0.404 * *$ & $0.505^{* *}$ \\
\hline \multicolumn{4}{|l|}{ Occupation } \\
\hline \multicolumn{4}{|l|}{ Ref cat: Unemployed } \\
\hline Agricultural/Factory workers & & $-0.164 * *$ & $-0.172 * *$ \\
\hline Professional & & -0.083 & -0.059 \\
\hline Others & & $-0.249 * *$ & $-0.240 * *$ \\
\hline \multicolumn{4}{|l|}{$\underline{\text { Number of living children }}$} \\
\hline \multicolumn{4}{|l|}{ Ref cat: $<3$} \\
\hline $3-4$ & & & $-0.127 * *$ \\
\hline $5+$ & & & $-0.243 * *$ \\
\hline \multicolumn{4}{|l|}{ Religion } \\
\hline \multicolumn{4}{|l|}{ Ref cat: Muslim } \\
\hline Others & & & $-0.071 * *$ \\
\hline \multicolumn{4}{|l|}{$\underline{\text { Region }}$} \\
\hline Rajshahi & & & $-0.390 * *$ \\
\hline Barisal & & & $-0.597 * *$ \\
\hline Sylhet & & & -0.043 \\
\hline Khulna & & & $-0.343 * *$ \\
\hline Chittagong & & & $-0.191 * *$ \\
\hline \multicolumn{4}{|l|}{ Ref cat: Dhaka } \\
\hline Intercept & $-0.430 * *$ & $-0.828 * *$ & $-0.649 * *$ \\
\hline Adjusted R2 & 0.384 & 0.533 & 0.560 \\
\hline$F$ for $R 2$ change & $2514.5^{* *}$ & $280.8 * *$ & $61.01 * *$ \\
\hline
\end{tabular}

Levels of Statistical Significance: $* * \mathrm{P}<0.01$ 
the significant advantage also observed for rural-urban migrants and urban natives over rural natives remained but the values decrease. In all models, rural-urban migrants indicate lower degree of association with better living conditions relative to urban natives but higher degree of association with better living conditions than the rural natives. All of the results are found statistically significant. Thus it reveals that migration may be relevant for improving the living condition in Bangladesh if migrants are educated and professional/housewife. However, with low levels of education, poor economic opportunities and high levels of unemployment in the rural areas the rural natives may not improve living conditions. It may worsen the situation. An interesting relationship is identified between household structure and living conditions. As number of living children increases' living conditions decreases and this is significant for the largest households of over five living children. This outcome is similar to the modernization paradigm that small-sized family norms should improve living standards. A methodological contribution of this study is the empirical consistency of the poverty estimates. Through the use of the household asset-measure of poverty, the regional variations in living conditions identified. With "Dhaka" as the reference category, this study shows "Barisal", "Rajshahi" and "Khulna" as the region's most vulnerable to poverty. Finally, the high levels of living conditions in "Sylhet" raised the genuine concern about the validity of the estimates. This outcome continues to reiterate the increasing concern about the rural to urban migration in developing countries. In sum, the regional imbalance identified in this analysis, underscores the magnitude of policy efforts needed to promote development and address issues related to living conditions' inequity in Bangladesh.
Thousands of jobless people migrate from rural to urban areas in search for jobs in Bangladesh. Most of them are street beggars, venders, rickshaw pullers, and garment workers. The limitation of this study is that this group of people was not included in our analysis because the information on this group is not available in the data BDHS 2007. For further research, one may compare the results obtained in this study with other developing countries.

1. Gurmu, E., Sidney Goldstein and Alice Goldstein, 2000. Migration, Gender and Health Survey in Five Regions of Ethiopia: 1998. (A United Nation Training and Research Project on the interrelations of Migration and Economic Change, Women's Status, Reproduction and Health). Addis Ababa: Addis Ababa University and Providence: Brown University.

2. Gage, J.A., E. Sommerfelt and A.L. Paini, 1997. Household Structure and Childhood Immunization in Niger and Nigeria. Demography 34 (2): 295-309.

3. Nigeria Institute of Social and Economic Research (NISER), 2003. Understanding Poverty in Nigeria. Ibadan: NISER.

4. Montgomery, M, M. Gragnolati, K. Burke, and E. Paredes, 2000. Measuring Living Standards with Proxy Variables. Demography, 37 (2): 155-174.

5. Gwatkin, D.R., S. Rustein, K. Johnson, R.P. Pande, and A. Wagstaff, 2000. Socioeconomic Differences in Health, Nutrition, and Population in Kenya. Washington, DC: HNP/Poverty Thematic Group, The World Bank.

6. Rutstein, S, 1999. Wealth versus expenditure: Comparison between the DHS wealth index and household expenditures in four departments of Guatemala. Calverton, Maryland, USA: ORC Macro (Unpublished).

7. Rutstein, S., and K. Johnson, 2004. The DHS wealth index. DHS Comparative Reports No. 6. Calverton, Maryland: ORC Macro. 